\title{
Botulinum Toxin A for the treatment of neurogenic detrusor overactivity in multiple sclerosis patients
}

\author{
S. Deffontaines-Rufin, M. Weil, D. Verollet, L. Peyrat, G. Amarenco \\ Service de Rééducation Neurologique et d'Explorations Périnéales (SDR, MW, DV, GA), and Service \\ d'urologie (LP), Hôpital TENON, Paris, France
}

\begin{abstract}
Purpose: Neurogenic detrusor overactivity (NDO) is common in patients who suffer from multiple sclerosis (MS). When the usual pharmacological treatment fails, botulinum toxin type A (BTX-A) injections can be proposed. The safety and efficacy of this treatment are already well known, but only a few studies focus on its use in patients with MS.

Materials and Methods: Seventy-one patients with MS underwent their first BTX-A injection for refractory NDO. They had clinical and urodynamic cystometry assessment before and three months after injection. The patients were divided in three groups according to treatment efficacy: full success (total urinary continence, no overactive detrusor), improvement, or total failure (urge incontinence and overactive detrusor).

Results: $77 \%$ of the patients had clinical improvement or full success of the treatment with a reduction of their urgency and incontinence. Significant urodynamic improvement after treatment was shown on different parameters: volume at first involuntary bladder contraction $(\mathrm{p}=0.0000001)$, maximum cystometric capacity $(\mathrm{p}=0.0035)$, maximum detrusor pressure $(p=0.0000001) .46 \%$ of the patients were in the "full success" group. $31 \%$ of the patients had a partial improvement. $23 \%$ of the patients had no efficacy of the treatment. Duration of MS was a predictive factor of treatment failure $(\mathrm{p}=0.015)$.

Conclusions: Despite that a full success was obtained in $46 \%$ of the cases, BTX-A injection therapy failed to treat refractory NDO in $23 \%$ of patients suffering from MS. Duration of the disease was a predictive factor for an inefficient treatment. The injection therapy should be considered as soon as oral anticholinergic drugs fail to reduce NDO.
\end{abstract}

Key words: kidney; multiple sclerosis; botulinum toxins; urinary bladder; neurogenic; administration; intravesical; treatment outcome

Int Braz J Urol. 2011; 37: 642-648

\section{INTRODUCTION}

Multiple sclerosis (MS) is a common demyelinating disease of the central nervous system. The lesions occur in different time and localization in subcortical areas, brain stem and spinal cord. The disease has varied clinical presentations (1). Bladder and urethra dysfunction are very common. Detrusor overactivity is the most common urodynamic sign. It is observed in $44 \%$ (2) to $81 \%$ (3) of patients. Detrusor sphincter dyssynergia is associated with overactive detrusor in $93 \%$ of cases (2).

Detrusor overactivity is often associated with overactive bladder, defined by urgency, possibly associated with urge incontinence, daytime frequency, and nocturia (4). These symptoms significantly alter the quality of life (5). Urological complications including hydronephrosis, vesicoureteral reflux, urosepsis, and urolithiasis (6) occur in $12 \%$ of the patients who suffer from neurogenic detrusor overactivity (NDO) and MS (7). The rate 
of upper urinary tract involvement is lower in patients with MS than in patients with spinal cord injury (SCI), without a clear explanation (8).

Anticholinergic agents are the first line of treatment for NDO. If not sufficient, a combination of anticholinergic agents therapy can be tried (6). Anticholinergic agents can cause side effects that forbid their use, as on the central nervous system (memory and cognition alteration) or on the heart (prolongation of QT interval) (9). Electrical stimulation is an alternative, but often insufficient (8). When usual treatments fail, the NDO is considered as refractory, and the use of bladder botulinum toxin-type A (BTX-A) injection is nowadays recommended with a good level of proof (10). BTX-A formulation Botox is usually used. The efficacy of this treatment versus placebo (11) and resiniferatoxin injection therapy (12) has been demonstrated. Gomes et al compared the use of two different BTX-A formulations (Botox ${ }^{\circledR}$ and Prosigne ${ }^{\circledR}$ ). Botox treatment resulted in significantly greater increase of urodynamics parameters, and a tendency for better results in terms of continence rate (13).

In patients suffering from NDO, the use of intra detrusor BTX-A injection improves continence in $60 \%$ to $80 \%$ of the patients, with total continence in $42 \%$ to $87 \%$ of the patients. Quality of life is improved in $35 \%$ to $65 \%$ of the patients (14). Up to $70 \%$ of patients stop their anticholinergic drugs after BTX-A treatment (15). BTX-A bladder injection reduces the incidence of symptomatic urinary tract infections (16). The effect lasts between six and 12 months in smooth muscle, such as the bladder $(6,17)$. In the literature, the populations studied are mostly composed of patients suffering from SCI (57\%) and fewer patients suffering from MS (17\%) (14). Reports focused on the use of BTX-A bladder injection therapy in NDO due to MS are sparse (18). In three studies, clinical and urodynamical efficacy of BTX-A therapy in patients suffering from NDO in MS has been shown (19-21).

The objective of the present report is to evaluate the clinical and urodynamical response to the first BTX-A injection of patients suffering from refractory NDO in MS.

\section{MATERIALS AND METHODS}

After local ethical committee approval, 71 patients suffering from MS and complained of urgency, daytime frequency and urge incontinence due to refractory NDO were included in the study. NDO was considered as refractory when at least two anticholinergic agents each taken correctly for at least two months followed by an association of these two agents for at least two months failed to reduce clinical and urodynamical symptoms.

All the patients received their first BTXA bladder injection. Anticholinergic medications that would interfere with urovesical function were stopped at least one week before BTX-A injection.

Data were collected with a retrospective methodology.

\section{Technique}

The absence of urinary tract infection or any anticoagulant treatment were checked before the injection. For each patient a dose of 300 UI of BTX-A (Botox ${ }^{\circledR}$ ) diluted in $30 \mathrm{~mL}$ of saline was injected in thirty detrusor sites sparing the trigone, during a cystoscopy. Analgesia by inhaled nitrous oxide (Kalinox $\left.{ }^{\circledR}\right)$ was always proposed, in order to avoid pain during injection.

All the patients were able to practice intermittent self-catheterization (ISC) before the injection therapy, to manage the possible increase of post-void residual volume after injection.

\section{Evaluation}

The patients had clinical and urodynamic assessment one month before and three months after BTX-A injection. Two weeks before treatment, the patients were trained in ISC, by a nurse. Later examinations were not reported, as this study focuses on the response to the treatment. Urodynamic investigations were done complying with ICS recommendations (17).

Age, sex, and the time interval since the first neurological symptoms occurred was noted for each patient. 
Before each visit the patients made a bladder diary during three days, as described by Abrams (4). The mean number of urge urinary incontinence episode was estimated for each patient, at each visit.

Urodynamic data were collected: volume at first involuntary bladder contraction (FCV), maximal detrusor pression during filling ( $\mathrm{P}$ det. max.), maximal cystometric bladder capacity (MCC).

Treatment efficacy was judged three months after the first injection. Patients were sorted into three groups, according to the result of the treatment. The first group is the "full success" group, in which urge urinary incontinence totally disappeared and urodynamic assessment demonstrated no involuntary bladder contraction. In the second group, called the "improvement" group, the patients described a reduction of $50 \%$ of urge urinary incontinence episodes. The urodynamic parameters were improved: FCV and MCC were at least $50 \%$ higher, and P detmax decreased at least $50 \%$, compared to the pre treatment evaluation. The third group was called "total failure" group, as the patients complained of unchanged incontinence, and/or urodynamic assessment was similar to the first one.

\section{Statistics}

The Student t-test was used to compare means of values with Gaussian distribution. The chisquare test was used to compare independence of parameters. The significance was assumed if $\mathrm{p}<0.05$.

\section{RESULTS}

Fifty-two women and 19 men were studied, with a mean age of 47.6 years (standard deviation -SD:11.2). 66 patients (93\%) complained of urgency with urge incontinence associated with slow or intermittent stream. For these patients, the initial urodynamic assessment showed detrusor overactivity and detrusor sphincter dyssynergia. Out of them, 64 patients practiced non-exclusive intermittent self-catheterization, and two had total urinary retention requiring exclusive intermittent self catheterization. Five patients $(7 \%)$ complained of urgency and urge incontinence, due to detrusor overactivity without detrusor sphincter dyssynergia.

The injection therapy improved significantly FCV, MCC, and P det. max. (Table-1) All of the patients needed intermittent self-catheterization after injection. No other relevant side effect was observed.

After BTX-A injections, 55 patients (77\%) had a significant clinical improvement, with a decrease of their daily urge incontinence of at least $50 \%$. Among those patients, 33 had a total continence, and no involuntary bladder contraction on urodynamical assessment. These patients (46\%) were assigned to group 1, the "full success" group. Twenty-two patients (31\%) were assigned to group 2 , “improvement". Sixteen patients $(23 \%)$ were assigned to group 3, "total failure" (Table 2).

Table 1 - Global results. Urodynamics efficacy of the injection therapy in 71 patients with MS and refractory overactive detrusor.

Before injection

Mean FCV (mL) / SD

Mean MCC $(\mathrm{mL}) / S D$

Mean $\mathrm{P}$ det. max. $\left(\mathrm{cm} \mathrm{H}_{2} \mathrm{O}\right) / S D$
$159 / 83$

$240 / 130$

$61 / 23$
After injection

$301 / 120$

$328 / 114$

$36 / 27$

\section{p}

$\mathrm{p}<0.001$

$\mathrm{p}<0.001$

$\mathrm{p}<0.001$ 
Botulinum toxin in multiple sclerosis patients

Table 2 - Group analysis: repartition of the patients and demographic data.

\begin{tabular}{lcccc}
\hline & Full Success & Improvement & Failure & Statistics : p \\
\hline Number of patients/ $\%$ & $33 / 46 \%$ & $22 / 31 \%$ & $16 / 23 \%$ & \\
Sex & 25 women & 15 women & 12 women & $\mathrm{P}=0.81$ \\
& 8 men & 7 men & 4 men & \\
Mean age (years) / SD & $47 / 10.4$ & $46 / 12.1$ & $50.6 / 11.5$ & $\mathrm{P}=0.22$ \\
Mean duration of MS (years) / SD & $13.8 / 9$ & $11.7 / 9$ & $19.6 / 12.4$ & $\mathrm{P}<0.05$ \\
\hline
\end{tabular}

There was no statistical difference in the three groups concerning demographic data, or urodynamic parameters before injection.

In group 3 the duration of the disease was significantly longer than in the other two $(\mathrm{p}<$ $0.05)$. Therefore duration of the disease seems to be a predictive factor for treatment failure (Table 2 and 3 ).

\section{DISCUSSION}

The overall results of our study are consistent with previous reports, in terms of safety and efficacy of BTX-A treatment. Moreover, BTX-A bladder injections have comparable efficacy to treat NDO in patients suffering from SCI or from MS. Indeed, the overall efficacy of the treatment in SCI patients varies from $75 \%$ to $90 \%$ (22-24), which is consistent with $77 \%$ of efficacy of treatment in the present study.

Only three studies, of 16 patients (19), 43 patients (20), and 12 patients (21), focus on
MS patients. In these reports, as in the present one, clinical and urodynamic parameters were significantly improved by the treatment. Despite these excellent outcomes, not all of the patients were efficiently treated. This was consistent with $27.9 \%$ of the patients who needed anticholinergic medication in association with BTX-A therapy in the study by Kalsi (20).

In our study duration of MS was a predictive factor for failure of BTX-A treatment. A worsening of neurological and urinary conditions was associated with the duration of MS (2) and seemed to result in a more severe NDO than in the early stage of the disease. As the neurological condition progresses, the severity of the urinary symptoms increases (8), and renal complications of NDO are more frequent (3). This result is an argument for an earlier proposal of BTX-A injection therapy in refractory NDO due to MS. However, the study on rats from Temeltas did not find any histological difference of the bladder tissue after BTX-A injection either if the injection was

Table 3 - Group analysis. Mean urodynamic criteria before injection.

\begin{tabular}{lcccc}
\hline & Full Success & Improvement & Failure & Statistics : P \\
\hline Mean FCV $(\mathrm{mL}) / S D$ & $171.4 / 88$ & $139.4 / 84$ & $161.5 / 70$ & $\mathrm{P}=0.90$ \\
Mean MCC $(\mathrm{mL}) / \mathrm{SD}$ & $286.4 / 128$ & $202.4 / 131$ & $195 / 114$ & $\mathrm{P}=0.12$ \\
Mean P det. $\max .\left(\mathrm{cm} \mathrm{H}_{2} \mathrm{O}\right) / \mathrm{SD}$ & $61.7 / 20$ & $69 / 26$ & $64 / 22$ & $\mathrm{P}=0.92$ \\
\hline
\end{tabular}


made early or late after spinal injury (25). Still MS is a progressive disease, and the duration of the disease is associated with new neurological lesions.

In the present study all of the patients practiced ISC. The induced hypocontractility of the detrusor by the treatment led to urinary retention that often required intermittent self- catheterization (17).

Patients with MS often have an association of NDO and detrusor sphincter dyssynergia, which results in post-void residue. They are at very high risk of urinary retention. Up to $98 \%$ of patients with MS require ISC after BTX-A bladder injection (20). This raises the question about witch dosage of BTX-A should be applied. The use of BTX-A treatment in NDO was pioneered by Schurch et al. in 2000 (23). In this study, 200 or $300 \mathrm{U}$ of BTX-A (Botox, Allergan) was used in 19 patients with SCI, who already practiced ISC. The two patients who had a moderate improvement without complete continence had the lower dose of $200 \mathrm{U}$ (23). More recently, Menhert et al. treated 12 patients suffering from MS and NDO, using the dose of $100 \mathrm{U}$ of BTX-A. They showed significant improvement of cystometric and clinical parameters. Post-void residual volume increased, but most patients were able to remain on voluntary voiding. Two patients needed ISC once to twice daily on demand, one patient needed a supra pubic catheter (21). However, all patients in whom BTX-A treatment is planned should be taught ISC (21). Lekka and Lee reported three cases of severely disabled patients who had long term indwelling catheters. These patients were unable to do ISC, and suffered from incontinence despite the indwelling catheter. They were treated with BTX-A bladder injection and suprapubic catheterization. They all became pad-free (26). This management could be an alternative to surgical treatment as ileal cystoplasty.

No relevant complication was noted in the present study. The injections can be complicated with transient pain at the injection site (11), urinary tract infection ( 2 to $32 \%$ of the cases) (14), or haematuria (2 to $21 \%$ of the patients) (14). Other side effects of BTX-A injections are rare, such as allergic reaction to the toxin or transient flu. A few cases of generalized muscle weakness after bladder injections have been reported (17) and not observed in our series.

\section{CONCLUSIONS}

MS is a neurological central disease with disseminated lesions in time and space. NDO is frequent and causes overactive bladder syndrome with urgency, frequency, and urge incontinence. This alters quality of life. Upper urinary tract complications can occur. Therefore, NDO has to be efficiently treated. Usual medications as anticholinergic agents can fail. Refractory NDO is nowadays usually treated by BTX-A bladder injections.

BTX-A bladder injection therapy was efficient to treat refractory NDO in MS patients, with an overall efficacy of $77 \%$, in terms of clinical and urodynamic results. The efficacy of this treatment was similar to what is observed in patients suffering from SCI.

Still, $23 \%$ of the patients showed no improvement of their clinical symptoms and urodynamic parameters. A predictive factor of this bad response to treatment was the duration of MS. Duration of MS is also known to be associated with increased risk of upper urinary tract complications. This is an argument for an early proposal of BTX-A bladder injection therapy for refractory NDO in patients with MS.

\section{CONFLICT OF INTEREST}

None declared.

\section{REFERENCES}

1. Mallam E, Scolding N. The Diagnosis of MS. The International MS Journal. 2009; 16: 19-25.

2. Araki I, Matsui M, Ozawa K, Takeda M, Kuno S: Relationship of bladder dysfunction to lesion site in multiple sclerosis. J Urol. 2003; 169: 1384-7.

3. Giannantoni A, Scivoletto G, Di Stasi SM, Grasso MG, Vespasiani G, Castellano V: Urological dysfunctions and upper urinary tract involvement in multiple sclerosis patients. Neurourol Urodyn. 1998; 17: 89-98. 
4. Abrams P, Cardozo L, Fall M, Griffiths D, Rosier P, Ulmsten U, et al.: The standardisation of terminology of lower urinary tract function: report from the Standardisation Sub-committee of the International Continence Society. Neurourol Urodyn. 2002; 21: 167-78.

5. Cohen BA: Identification, causation, alleviation, and prevention of complications (ICAP): an approach to symptom and disability management in multiple sclerosis. Neurology. 2008; 71(24 Suppl 3): S14-20.

6. Kennelly MJ, Devoe WB: Overactive bladder: pharmacologic treatments in the neurogenic population. Rev Urol. 2008; 10: 182-91.

7. de Sèze M, Ruffion A, Denys P, Joseph PA, PerrouinVerbe B; GENULF: The neurogenic bladder in multiple sclerosis: review of the literature and proposal of management guidelines. Mult Scler. 2007; 13: 915-28.

8. DasGupta R, Fowler CJ: Sexual and urological dysfunction in multiple sclerosis: better understanding and improved therapies. Curr Opin Neurol. 2002; 15: 271-8.

9. MacDiarmid SA: How to choose the initial drug treatment for overactive bladder. Curr Urol Rep. 2007; 8: 364-9.

10. Apostolidis A, Dasgupta P, Denys P, Elneil S, Fowler $\mathrm{CJ}$, Giannantoni A, et al.: Recommendations on the use of botulinum toxin in the treatment of lower urinary tract disorders and pelvic floor dysfunctions: a European consensus report. Eur Urol. 2009; 55: 100-19.

11. Schurch B, de Sèze M, Denys P, Chartier-Kastler E, Haab F, Everaert K, et al.: Botulinum toxin type a is a safe and effective treatment for neurogenic urinary incontinence: results of a single treatment, randomized, placebo controlled 6-month study. J Urol. 2005; 174: 196-200.

12. Giannantoni A, Di Stasi SM, Stephen RL, Bini V, Costantini E, Porena M: Intravesical resiniferatoxin versus botulinum-A toxin injections for neurogenic detrusor overactivity: a prospective randomized study. J Urol. 2004; 172: 240-3.

13. Gomes CM, Castro Filho JE, Rejowski RF, TrigoRocha FE, Bruschini H, Barros Filho TE, et al.: Experience with different botulinum toxins for the treatment of refractory neurogenic detrusor overactivity. Int Braz J Urol. 2010; 36: 66-74.

14. Karsenty G, Denys P, Amarenco G, De Seze M, Gamé X, Haab F, et al.: Botulinum toxin A (Botox) intradetrusor injections in adults with neurogenic detrusor overactivity/neurogenic overactive bladder: a systematic literature review. Eur Urol. 2008; 53: 275-87.

15. Toh KL, Tow A: Variation between clinical and urodynamical responses in patients receiving intradetrusor botulinum-A for refractory neurogenic detrusor overactivity. Urology 2007 70( Suppl 3A): 228. Abstract 01.122

16. Gamé X, Castel-Lacanal E, Bentaleb Y, Thiry-Escudié I, De Boissezon X, Malavaud B, et al.: Botulinum toxin A detrusor injections in patients with neurogenic detrusor overactivity significantly decrease the incidence of symptomatic urinary tract infections. Eur Urol. 2008; 53: 613-8.

17. Sahai A, Khan M, Fowler CJ, Dasgupta P: Botulinum toxin for the treatment of lower urinary tract symptoms: a review. Neurourol Urodyn. 2005; 24: 2-12.

18. Giannantoni A, Mearini E, Del Zingaro M, Santaniello F, Porena M: Botulinum A toxin in the treatment of neurogenic detrusor overactivity: a consolidated field of application. BJU Int. 2008; 102 (Suppl 1): 2-6.

19. Schulte-Baukloh H, Schobert J, Stolze T, Stürzebecher B, Weiss C, Knispel HH: Efficacy of botulinum-A toxin bladder injections for the treatment of neurogenic detrusor overactivity in multiple sclerosis patients: an objective and subjective analysis. Neurourol Urodyn. 2006; 25: 110-5.

20. Kalsi V, Gonzales G, Popat R, Apostolidis A, Elneil S, Dasgupta $P$, et al.: Botulinum injections for the treatment of bladder symptoms of multiple sclerosis. Ann Neurol. 2007; 62: 452-7.

21. Mehnert U, Birzele J, Reuter K, Schurch B: The effect of botulinum toxin type a on overactive bladder symptoms in patients with multiple sclerosis: a pilot study. J Urol. 2010; 184: 1011-6.

22. Tow AM, Toh KL, Chan SP, Consigliere D: Botulinum toxin type A for refractory neurogenic detrusor overactivity in spinal cord injured patients in Singapore. Ann Acad Med Singapore. 2007; 36: 11-7.

23. Schurch B, Stöhrer M, Kramer G, Schmid DM, Gaul G, Hauri D: Botulinum-A toxin for treating detrusor hyperreflexia in spinal cord injured patients: a new alternative to anticholinergic drugs? Preliminary results. J Urol. 2000; 164: 692-7.

24. Patki PS, Hamid R, Arumugam K, Shah PJ, Craggs $\mathrm{M}$ : Botulinum toxin-type A in the treatment of drugresistant neurogenic detrusor overactivity secondary to traumatic spinal cord injury. BJU Int. 2006; 98: 77-82. 
25. Temeltas G, Tikiz C, Dagci T, Tuglu I, Yavasoglu A: The effects of botulinum-A toxin on bladder function and histology in spinal cord injured rats: is there any difference between early and late application? J Urol. 2005; 174: 2393-6.
26. Lekka E, Lee LK: Successful treatment with intradetrusor Botulinum-A toxin for urethral urinary leakage (catheter bypassing) in patients with end-staged multiple sclerosis and indwelling suprapubic catheters. Eur Urol. 2006; 50: 806-9; discussion 809-10.

Submitted for publication: November 25, 2010

Accepted after revision: February 09, 2011

\section{Correspondence address:}

Dr. S. Deffontaines-Rufin

Service de Rééducation Neurologique et d'Explorations Périnéales

Hôpital TENON

4 Rue de la Chine, Paris 20ème, France

Telephone: + 014 216-1149

E-mail: stephanie.deffontaines@psl.aphp.fr 